\title{
Effects of VBMDMP on the reversal of cisplatin resistance in human lung cancer A549/DDP cells
}

\author{
CHENG-KUN WANG ${ }^{1,2 *}$, YANG ZHANG ${ }^{2}$, ZHI-JIE ZHANG ${ }^{1}$, QIN-WEI QIU ${ }^{1}$, \\ JIAN-GUO $\mathrm{CAO}^{3 *}$ and ZHI-MIN HE ${ }^{1}$ \\ ${ }^{1}$ Cancer Research Institute, Affiliated Cancer Hospital of Guangzhou Medical University, Guangzhou, Guandong 510182; \\ ${ }^{2}$ Cancer Research Institute, University of South China, Hunan, Hengyang 421001; ${ }^{3}$ Medical College, \\ Hunan Normal University, Hunan, Changsha 410006, P.R. China
}

Received July 24, 2014; Accepted October 20, 2014

DOI: $10.3892 /$ or.2014.3607

\begin{abstract}
Tumor drug resistance is a major obstacle to cancer chemotherapy. We previously constructed a fusion protein based on two tumstatin-derived sequences named recombinant VBMDM (rVBMDMP). We preliminarily confirmed its inhibition of HUVEC and colon cancer cell growth. The present study further systematically observed the inhibitory effect of rVBMDMP on lung cancer cell growth and analyzed a possible mechanism to provide a theoretical basis for the development of new antitumor protein drugs. The effect of rVBMDMP on human lung adenocarcinoma (A549) and cisplatin-resistant human lung adenocarcinoma (A549/DDP) cell proliferation was evaluated by MTS assay. Hoechst 33342 staining performed together with fluorescence microscopy and immunoblot analysis were used to examine the effects of rVBMDMP on the apoptosis of A549/DDP cells. A protein phosphorylation chip was used to identify changes in rVBMDMP-induced signaling protein phosphorylation. Changes in the phosphatidylinositol 3 kinase (PI3K)/Akt signal transduction pathway and expression of multidrug resistance protein (MRP-2)-related molecules following rVBMDMP treatment in A549/DDP cells were evaluated by western blot analysis. A lung cancer xenograft model was used to evaluate the reversal effect of rVBMDMP on drug-resistance of A549/ DDP cell tumors to cisplatin in vivo. The results demonstrated that rVBMDMP increased the phosphorylation of 79 signaling proteins, including focal adhesion kinase (FAK), caspase-6, Fas, FasL and FAF1 and downregulated 30 signaling proteins,
\end{abstract}

Correspondence to: Professor Zhi-Min He, Cancer Research Institute, Affiliated Cancer Hospital of Guangzhou Medical University, 78 Hengzhigang Road, Guangzhou, Guangdong 510095, P.R. China E-mail: hezhimin2005@yahoo.com

*Contributed equally

Key words: lung carcinoma, recombinant vascular basement membrane-derived multifunctional peptide, polypeptide drug, reversal of multidrug resistance including integrin $\alpha \mathrm{V}$, integrin $\beta 3$, PI3K/Akt, NF- $\kappa \mathrm{B}$ and MRP-2 compared with the controls. rVBMDMP also increased the sensitivity of A549 and A549/DDP cells to cisplatin and directly induced apoptosis, which may be related to MRP-2 and Bcl-2 downregulation. The effects of growth inhibition and apoptosis induction of rVBMDMP on A549/DDP cells may be related to the inhibition of integrin $\alpha \mathrm{V} \beta 3$ and PI3K/Akt protein phosphorylation. Finally, we observed an increase in cancer cell sensitivity to cisplatin by rVBMDMP using the A549/DDP cell xenograft model in nude mice. Our study suggests that rVBMDMP may be an effective potential chemotherapy sensitizer and may be a viable drug candidate in anticancer therapies.

\section{Introduction}

Based on the strategy of targeting both proliferating tumor cells and endothelial cells in our previous studies, we constructed a fusion protein of the human IgG3 upper hinge region and 2 tumstatin-derived specific sequences, which we named vascular basement membrane-derived multifunctional peptide (VBMDMP) (1). Recombinant VBMDMP (rVBMDMP) was found to exhibit anti-proliferation and anti-angiogenic activities and to significantly inhibit tumor growth and metastasis in a mouse lung carcinoma model (2). Moreover, rVBMDMP selectively inhibited endothelial cell and human colon cancer cell proliferation, induced endothelial cell apoptosis in vitro and suppressed human colon cancer xenograft growth in Balb/c-nu mice (3). We determined that the interaction of rVBMDMP with $\alpha \mathrm{V} \beta 3$ integrin is critical for rVBMDMP binding to cells and mediates the rVBMDMP-induced inhibition of proliferation (4).

Integrins are a family of heterodimeric transmembrane proteins comprising unrelated $\alpha$ and $\beta$ subunits that serve as receptors for extracellular matrix (ECM) proteins such as fibronectin (FN), laminins and collagens. In mammals, 18 types of $\alpha$ subunits and 8 types of $\beta$ subunits assemble to form 24 different receptors. Integrins initiate a variety of downstream signaling events including survival or death pathways in response to ECM ligation (5). The integrin $\alpha \mathrm{V} \beta 3$ receptor is implicated in cardiovascular and bone function and recognizes glycoprotein ligands such as vitronectin and 
FN. Upon activation of the integrin $\alpha \mathrm{V} \beta 3$ receptor, downstream molecules, including phosphatidylinositol 3 kinase (PI3K)/Akt, are phosphorylated, which increases cell tolerance to chemotherapy, resulting in secondary resistance in a variety of ways (6). In our previous study, we demonstrated that rVBMDMP binds $\alpha v \beta 3$ integrins and enhances the growth inhibitory activity of cisplatin in A549 cells (7). We also found that the expression of the multidrug resistance protein 2 (MRP-2) showed a downward trend in A549 cells following treatment with rVBMDMP (unpublished data).

MRP-2 is a member of the ATP-binding cassette (ABC) transporter superfamily. ABC genes are divided into 7 distinct subfamilies (ABC1, MDR/TAP, MRP, ALD, OABP and GCN20) and encode proteins that transport various molecules across extracellular and intracellular membranes (8). MRP-2 is a member of the MRP subfamily, which is involved in multidrug resistance (9). Its substrates include anticancer drugs, such as vinblastine and thus MRP-2 contributes to drug resistance in mammalian cancer cells. Therefore, we speculated that the rVBMDMP-mediated inhibition of MRP-2 has the potential to reverse tumor cell resistance to chemotherapeutic drugs.

In the present study, we demonstrated that rVBMDMP inhibited cisplatin-resistant A549/DDP human lung carcinoma cell proliferation using in vitro and in vivo models of tumor growth. We also demonstrated that rVBMDMP potently reversed A549/DDP cisplatin resistance by inhibiting MRP-2 expression, which may occur via the PI3K/Akt pathway. These data suggest that rVBMDMP could be a potentially useful therapeutic molecule targeting human lung cancer.

\section{Materials and methods}

rVBMDMP. rVBMDMP (6.4 kDa) was produced in BL-21 E. coli using the pGEX-4T-1-VBMDMP expression plasmid and purified as previously described (1).

Cell culture. Human lung carcinoma cells (A549) and cisplatin-resistant human lung carcinoma cells (A549/DDP) were obtained from the China Center for Type Culture Collection (CCTCC, Wuhan, China) and maintained in RPMI-1640 medium (Gibco-BRL, Grand Island, NY, USA), supplemented with $10 \%(\mathrm{v} / \mathrm{v})$ dialyzed heat-inactivated bovine serum (BS) (Gibco), $100 \mathrm{U} / \mathrm{ml}$ penicillin and $100 \mu \mathrm{g} / \mathrm{ml}$ streptomycin at $37^{\circ} \mathrm{C}$ in $5 \% \mathrm{CO}_{2}$.

Cell viability assay. Cell viability was determined using the MTS assay. In brief, $1.0 \times 10^{4}$ A549 and A549/DDP cells/well were plated in 96-well plates and incubated overnight. Cells were treated with various concentrations of rVBMDMP and cisplatin for $48 \mathrm{~h}$, and $20 \mu \mathrm{l}$ of 3-(4,5-dimethylthiazol-2-yl)-2,5-diphenyltetrazolium bromide [MTS, $5 \mathrm{~g} / 1$ in phosphate-buffered saline (PBS)] (Promega, Madison, WI, USA) was added. The plates were incubated for $6 \mathrm{~h}$, and the formed formazan dye was dissolved in $100 \mu 1$ of DMSO (Sigma-Aldrich, St. Louis, MO, USA). Absorbance was recorded at $570 \mathrm{~nm}$ using a Biotek Synergy 2 microplate reader (Biotek Instruments, Winooski, VT, USA). All experiments were repeated 3 times. Cell viability was calculated as: Cell viability rate $(\%)=(\mathrm{T}-\mathrm{B}) /(\mathrm{U}-\mathrm{B}) \times 100 \%$; where $\mathrm{T}$ is the treated cell absorbance, $\mathrm{U}$ is the untreated cell absorbance and
B is the background absorbance when neither drug nor MTS was added.

Signal transduction antibody array. Serum-starved A549 cells were treated with $10 \mu \mathrm{mol} / 1 \mathrm{rVBMDMP}$ for $30 \mathrm{~min}$, which was optimal for inhibiting endothelial cell proliferation and were lysed in $0.5 \%$ Triton X-100 buffer. This rVBMDMP concentration was determined to be optimal at inhibiting A549 cell proliferation in this study. The antibody array membrane (HM3000 signal transduction antibody array; Hypromatrix Inc., Worcester, MA, USA) was treated in blocking buffer containing $0.01 \%$ Tween-20 followed by incubation with sample diluted in $1 \%$ dry milk/PBS for $2 \mathrm{~h}$ at room temperature with slow shaking at $40 \mathrm{rpm}$. After the antibody filters were incubated with the supernatant protein solution at room temperature for $2 \mathrm{~h}$, the antibody array filter was washed with TBST and blotted with HRP-conjugated anti-phospho-tyrosine monoclonal antibodies for $2 \mathrm{~h}$. Anti-phospho-tyrosine reactivity was visualized by enhanced chemiluminescence (ECL; Amersham Biosciences) and exposed to X-ray film. The gray-scale chip scanogram was analyzed with chip image analysis software (QuantArray, Packard Biochip Technologies Inc. USA) to correct for protein signals. Immunoreactivity on the chip that had been incubated with control cell lysate was set to 1 for each spotted antibody. Phosphorylation ratios $>2$ or $<0.5$ were considered to indicate increased or decreased phosphorylation, respectively.

Western blot analysis. The anti-integrin $\alpha \mathrm{V}$, anti-integrin $\beta 3$, anti-MRP-2, anti-NF $\kappa \mathrm{B}$, anti-caspase 3, anti-PARP, anti-bcl2, anti-Akt, anti-p-Akt, anti-PI3K, anti-pPI3K and anti- $\beta$-actin antibodies were purchased from Santa Cruz Biotechnology (Santa Cruz, CA, USA). An anti-GAPDH antibody (Upstate Biotechnology, Lake Placid, NY, USA) was used as a loading control. After the treatments, the cells were collected and lysed. Approximately $100 \mathrm{ng}$ of total protein was electrophoresed on a $10 \%$ SDS-PAGE gel and then transferred to a PVDF membrane. After blocking the membrane with 5\% nonfat milk in PBS $+0.1 \%$ Tween-20 overnight at $4^{\circ} \mathrm{C}$, the blot was incubated with the primary antibody for $1 \mathrm{~h}$, washed with PBS $+0.1 \%$ Tween-20 3 times (15 min each time), incubated with the secondary antibody (IgG) conjugated with horseradish peroxidase for $1 \mathrm{~h}$ and washed with $\mathrm{PBS}+0.1 \%$ Tween-20 3 times. The signal was visualized with a chemiluminescence kit (SuperSignal, Pierce).

In vivo tumor growth inhibition studies. Female 6-week old Balb/c-nu mice weighing $\sim 16 \mathrm{~g}$ were implanted with $2 \times 10^{6}$ A549/DDP human lung cancer cells into the subcutis on the back. Tumor length and width were measured using a vernier caliper, and the tumor volume was calculated using the standard formula of length $\mathrm{x}$ width $^{2} \mathrm{x} 0.52$ (10). When the tumors were $\sim 100 \mathrm{~mm}^{3}$, the animals were divided into groups of 5 mice. rVBMDMP ( $5 \mathrm{mg} / \mathrm{kg})$, the angiogenesis inhibitor TNP-470 (20 mg/kg), cisplatin (10 mg/kg), a combination of rVBMDMP (5 mg/kg) and cisplatin $(10 \mathrm{mg} / \mathrm{kg})$ and vehicle control were administered via intravenous injection twice daily for 16 days. Mice were weighed twice weekly. Tumor volume was calculated every 3 days. Tumor volume \pm SD was plotted vs. time over the treatment period. Upon treatment termination, 

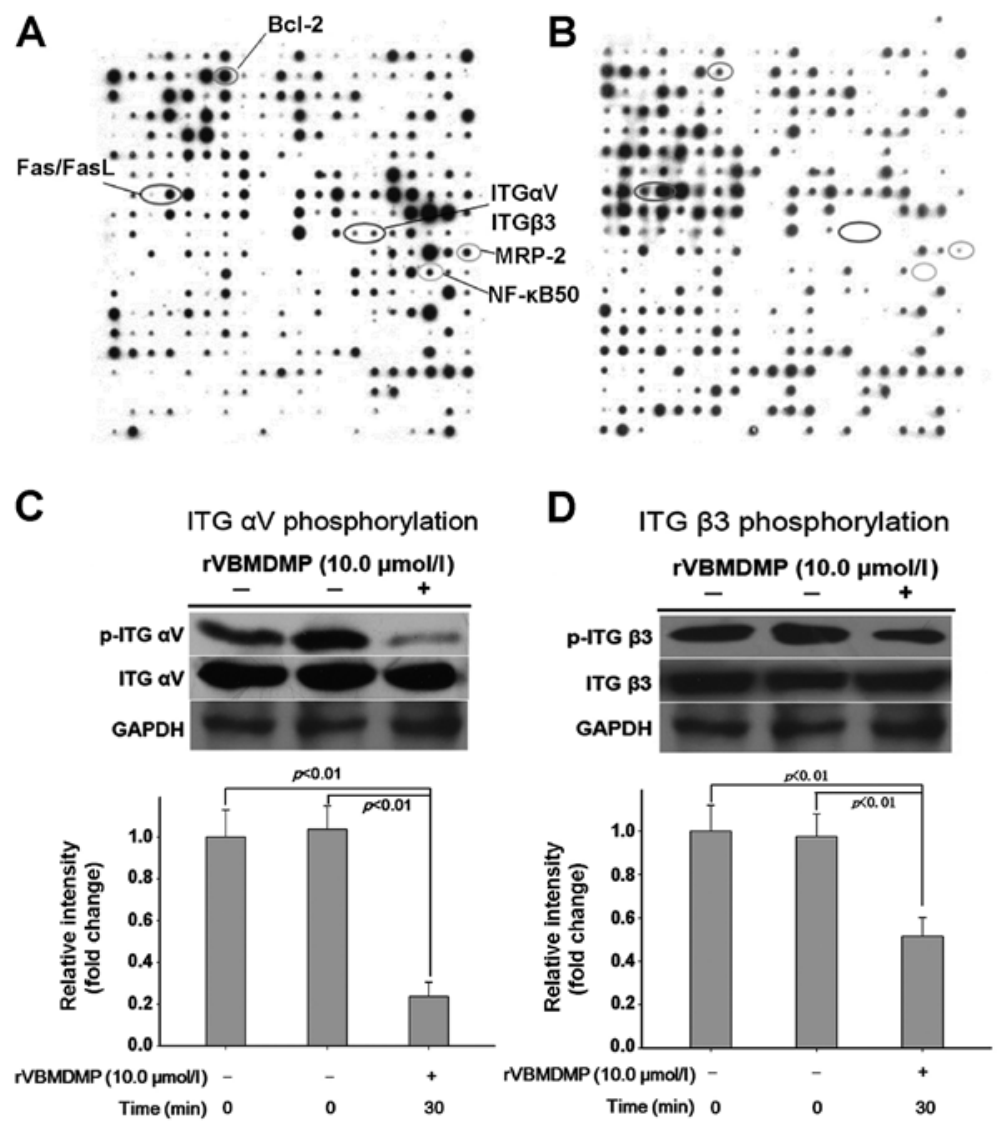

E

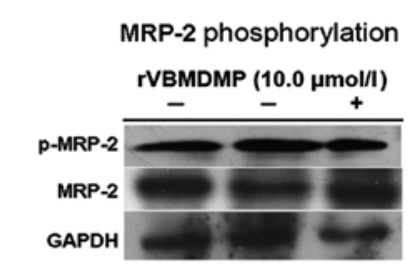

$\mathbf{F}$
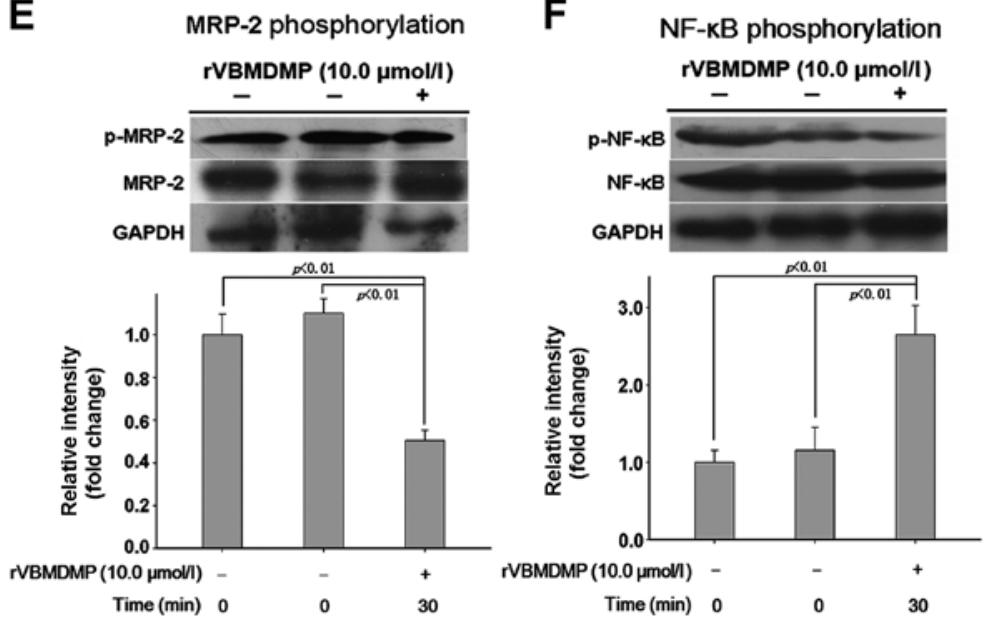

Figure 1. Signal transduction antibody array and immunobloting. (A and B) X-ray film of protein phosphorylation antibody chips: untreated controls (A) and $10 \mu \mathrm{mol} / 1 \mathrm{rVBMDMP}$ (B). (C and D) Immunoblots for phospho-integrin $\alpha \mathrm{V}$ (C) and phospho-integrin $\beta 3$ (D) show that $10 \mu \mathrm{mol} / 1 \mathrm{rVBMDMP}$ inhibited integrin $\alpha \mathrm{V}$ and integrin $\beta 3$ phosphorylation. ITG, integrin. (E and F) Phospho-MRP-2 and phospho-NF-kB immunoblots show that rVBMDMP significantly increased multidrug resistance protein 2 (MRP-2) and NF- $\mathrm{BB}$ phosphorylation. (C-F) Bar charts under the immunoblots show quantification of protein levels. Expression of each protein was normalized to the GAPDH level and the control was set to 1 . The mean of 3 separate experiments is shown. Student's t-test was used to evaluate statistical significance $(\mathrm{n}=3)$. rVBMDMP, recombinant VBMDMP.

the mice were weighed and sacrificed and their tumors were excised, weighed and photographed. The mean tumor weight per group was calculated. The mean ratio of the treated tumor weight to the mean vehicle control tumor weight x 100 was subtracted from $100 \%$ to provide the tumor growth inhibition for each group. All images were captured with a Canon digital camera and developed with Kodak 400 DK-coated TMAM. The experiments were performed using 5 mice per group and all animal procedures were performed in accordance with institutional guidelines. The study protocol was approved by the Ethics Committee of Guangzhou Medical University.

Statistical analysis. Continuous data are expressed as the mean \pm SD. Comparisons between groups were performed using the Student's t-test. Analysis of variance was used to examine differences in response to treatments and between groups. P-values $<0.05$ were considered to indicate statistically significant results. 
A
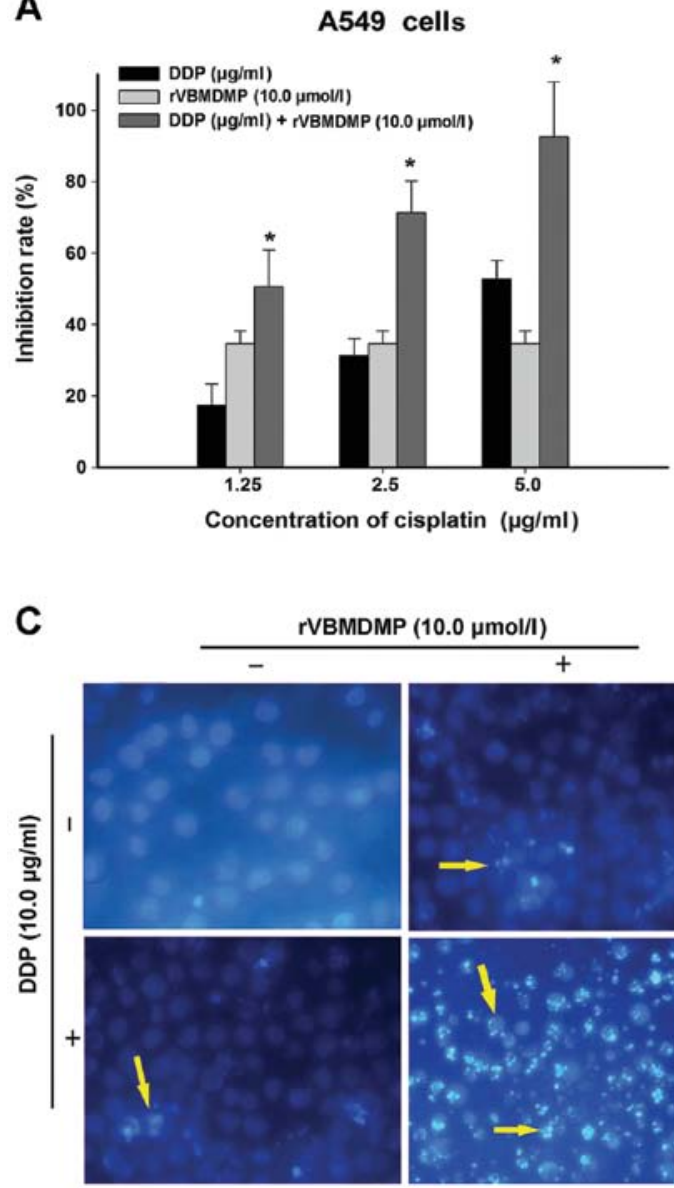

B

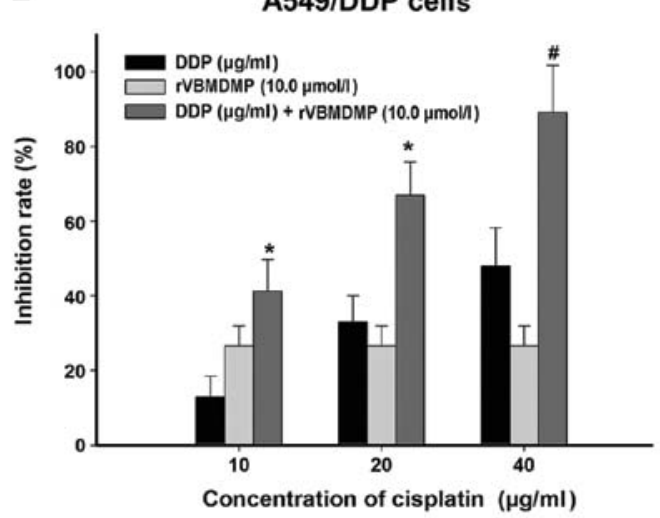

D

Figure 2. Effect of cisplatin combined with rVBMDMP on A549/DDP cell proliferation. (A and B) Effects of cisplatin, rVBMDMP or cisplatin combined with rVBMDMP on the proliferation of A549 (A) and A549/DDP cells (B). Values are expressed as mean \pm SD ( $=4$ ). ${ }^{*} \mathrm{P}<0.01$ vs. control (Student's t-test). (C) A549/DDP cells were cultured with RPMI-1640 with cisplatin, rVBMDMP or the combination of cisplatin and rVBMDMP as indicated for 48 h. Cell apoptosis was observed by Hoechst 33258 staining. Arrowheads indicate cells with abnormal nuclei, indicating fragmentation of nuclei/chromatin. (D) A549/ DDP cells were treated as in C, collected and subjected to western blot analyses with specific antibodies directed against caspase-3, PARP and $\beta$-actin. DDP, cisplatin; rVBMDMP, recombinant VBMDMP.

\section{Results}

rVBMDMP treatment alters the phosphorylation of signaling proteins. To explore the molecular mechanism of rVBMDMP-mediated lung cancer inhibition, we examined the effects of rVBMDMP on the phosphorylation of 400 signaling proteins using a protein phosphorylation chip (Fig. 1A and B). rVBMDMP treatment increased phosphorylation (defined as a 2-fold or higher increase compared with the controls) of focal adhesion kinase (FAK), caspase-6, Fas, FasL and FAF1. rVBMDMP treatment decreased phosphorylation (defined as a 0.5 -fold or more decrease compared with the controls) of integrin $\alpha \mathrm{V}$, integrin $\beta 3$, PI3K/Akt, NF- $\mathrm{BB}$ and MRP-2 (Table I). Western blot analysis confirmed that treatment with $10 \mu \mathrm{g} / \mathrm{ml}$ rVBMDMP for 30 min was sufficient to inhibit integrin $\alpha \mathrm{V}$, integrin $\beta 3, \mathrm{MRP}-2$ and NF- $\mathrm{B}$ phosphorylation (Fig. 1C-F). These results were concordant with the antibody microarray data.

rVBMDMP promotes A549/DDP cell cisplatin sensitivity and apoptosis. We treated A549/DDP cells with cisplatin concentrations of 5,10, 20 and $40 \mu \mathrm{g} / \mathrm{ml}$ and determined that higher cisplatin concentrations inhibited A549/DDP cell proliferation.
The concentrations of cisplatin required for A549/DDP cell growth inhibition were significantly higher than those required to inhibit A549 cell proliferation (Fig. 2A). After treating A549/DDP cells with $20 \mu \mathrm{g} / \mathrm{ml}$ cisplatin for $48 \mathrm{~h}$, the growth inhibition rate was $32.9 \pm 7.1 \%$, which increased with increasing cisplatin concentration (Fig. 2B). According to the formula $\mathrm{IC}_{50}=\lg ^{-1}$ [Xm-i (P-0.5)], the $\mathrm{IC}_{50}$ in A549/DDP cells treated with cisplatin for $48 \mathrm{~h}$ was $31.19 \mu \mathrm{g} / \mathrm{ml}$. The resistance index of A549/DDP cells to cisplatin was the $\mathrm{IC}_{50}$ of A549/DDP cells divided by $\mathrm{IC}_{50}$ of the A549 cells or $31.19 / 4.614 \mu \mathrm{g} / \mathrm{ml}=6.759$. This result demonstrates that the A549/DDP cell line has a certain resistance to cisplatin, which was suitable for this drug resistance study.

Next, A549/DDP cells were treated with $10 \mu \mathrm{M} \mathrm{rVBMDMP}$ along with 10, 20 or $40 \mu \mathrm{g} / \mathrm{ml}$ cisplatin for $48 \mathrm{~h}$ (Fig. 2B, Table II). When A549/DDP cells were treated with $10 \mu \mathrm{g} / \mathrm{ml}$ cisplatin alone, the growth inhibition rate was $12.8 \pm 5.6 \%$ and the inhibitory rate increased to $45.2 \pm 8.5 \%$ when combined with $10 \mu \mathrm{M}$ rVBMDMP. The Q value was 0.88. When A549/DDP cells were treated with $20 \mu \mathrm{g} / \mathrm{ml}$ cisplatin alone, the growth inhibition rate was $32.9 \pm 7.1 \%$ and the inhibitory rate increased to $66.9 \pm 8.9 \%$ when combined with $10 \mu \mathrm{M}$ rVBMDMP. The $\mathrm{Q}$ value was 1.15. When A549/DDP cells were treated with 
Table I. Ratios of cell signaling protein phosphorylation levels in A549 cells after $1.0 \mu \mathrm{mol} / \mathrm{l}$ VBMDMP treatment for 30 min.

\begin{tabular}{|c|c|c|c|}
\hline Position & Symbol & Ratio & Description and function \\
\hline 1 & $14-3-3$ & 3.90 & Critical for cell transformation and mitotic signaling \\
\hline 2 & $\mathrm{c}-\mathrm{Abl}$ & 2.44 & $\begin{array}{l}\text { Abelson murine leukemia virus; a } 120-\mathrm{kDa} \text { protein with tyrosine kinase activity } \\
\text { and an SH2 domain }\end{array}$ \\
\hline 42 & Brk & 2.31 & Human homolog of Sik (Src-related intestinal kinase) \\
\hline 43 & Brm & 2.03 & Similar to the brahma protein of Drosophila; helicase and ATPase activities \\
\hline 61 & Caspase-6 & 2.30 & Cysteine-aspartic acid protease 6 \\
\hline 72 & $\mathrm{CD} 27$ & 2.04 & $\begin{array}{l}\text { Homodimeric lymphocyte-specific surface antigen, belongs to the TNF receptor } \\
\text { superfamily }\end{array}$ \\
\hline 82 & $\mathrm{Cdk} 2$ & 2.66 & Cyclin-dependent protein kinase \\
\hline 89 & CIDE-B & 2.39 & A DNAse that is responsible for DNA degradation during apoptosis \\
\hline 90 & Clathrin & 2.12 & Clathrin \\
\hline 102 & Cyclin B & 3.56 & Cyclin protein $B$ \\
\hline 103 & Cyclin D3 & 3.52 & Cyclin protein D3 \\
\hline 104 & Cyclin E & 2.87 & Cyclin protein $\mathrm{E}$ \\
\hline 109 & Desmoglein & 2.33 & A member of the cadherin family of adhesion molecules \\
\hline 112 & DMBT1 & 2.05 & Deleted in malignant brain tumors 1 ; a candidate tumor-suppressor gene \\
\hline 121 & $\mathrm{E} 2 \mathrm{~F} 1$ & 2.28 & E2F transcription factor 1 \\
\hline 122 & EGFR & 4.13 & Epidermal growth factor receptor \\
\hline 123 & p-EGFR & 2.43 & Phosphorylated epidermal growth factor receptor \\
\hline 124 & Egr-1 & 3.93 & EGR family of $\mathrm{C} 2 \mathrm{H} 2$-type zinc-finger proteins, is a cancer suppressor gene \\
\hline 125 & Egr-2 & 4.25 & EGR family of $\mathrm{C} 2 \mathrm{H} 2$-type zinc-finger proteins, is a cancer suppressor gene \\
\hline 126 & Egr-3 & 4.52 & EGR family of $\mathrm{C} 2 \mathrm{H} 2$-type zinc-finger proteins, is a cancer suppressor gene \\
\hline 129 & EphA4 & 2.56 & Ephrin receptor A4 \\
\hline 130 & EphB1 & 5.24 & Ephrin receptor B1 \\
\hline 131 & Eps8 & 3.65 & Epidermal growth factor receptor substrate 8 \\
\hline 141 & FAF-1 & 6.64 & FAS interacting protein \\
\hline 142 & FAK & 5.50 & Focal adhesion associated protein-tyrosine kinase \\
\hline 143 & Fas & 5.08 & A member of the tumor necrosis factor family of cell surface receptors \\
\hline 144 & FasL & 2.27 & Fas ligand \\
\hline 146 & FGFR1 & 7.32 & Fibroblast growth factor receptor 1 \\
\hline 147 & FGFR2 & 2.70 & Fibroblast growth factor receptor 2 \\
\hline 148 & FGFR3 & 2.11 & Fibroblast growth factor receptor 3 \\
\hline 149 & FGFR4 & 3.23 & Fibroblast growth factor receptor 4 \\
\hline 150 & FHIT & 5.25 & A member of the histidine triad protein family; a candidate tumor suppressor \\
\hline 161 & GATA-1 & 4.05 & Transcription factor \\
\hline 162 & GATA-2 & 4.96 & Transcription factor \\
\hline 163 & GATA-3 & 7.17 & Transcription factor \\
\hline 164 & G-CSFR & 2.12 & Colony stimulating factor receptor \\
\hline 165 & gp130 & 2.30 & Glycoprotein 130 \\
\hline 166 & Granzyme B & 4.50 & Cytotoxic T-lymphocyte-associated serine esterase 1 \\
\hline 167 & GRB2 & 2.27 & Growth factor receptor-bound protein 2 \\
\hline 169 & GRB14 & 3.56 & Growth factor receptor-bound protein 14 \\
\hline 170 & GRK2 & 4.44 & G protein-coupled receptor kinase 2 \\
\hline 182 & IFN-aRa & 2.82 & Type I interferon $\alpha$ receptor $\alpha$ \\
\hline 183 & IFN-gRa & 7.28 & Type II interferon $\gamma$ receptor $\alpha$ \\
\hline 184 & IL1R1 & 4.64 & Interleukin-1 receptor 1 \\
\hline 186 & IL2R $\beta$ & 5.43 & Interleukin-2 receptor $\beta$ \\
\hline 187 & IL2R $\gamma$ & 3.77 & Interleukin-2 receptor $\gamma$ \\
\hline 188 & IL3 & 2.86 & Interleukin-3 \\
\hline 189 & IL4Ra & 2.06 & Interleukin-4 receptor $\alpha$ \\
\hline 202 & Jak1 & 2.65 & Janus kinase 1 \\
\hline 203 & Jak2 & 2.49 & Janus kinase 2 \\
\hline
\end{tabular}


Table I. Continued.

\begin{tabular}{|c|c|c|c|}
\hline Position & Symbol & Ratio & Description and function \\
\hline 206 & p-JNK1,2,3 & 2.13 & Phosphorylated c-Jun N-terminal kinases 1,2,3 \\
\hline 209 & KAP & 2.18 & A dual specificity phosphatase that interacts with cyclin-dependent kinases \\
\hline 222 & MEK1 & 2.08 & Mitogen-activated protein kinase kinase 1 \\
\hline 252 & Nip3 & 2.03 & $\begin{array}{l}\text { A member of the BCL2/adenovirus E1B } 19 \mathrm{kDa} \text {-interacting protein (BNIP) family, } \\
\text { Nip3 preferentially binds to Bcl-xL and induces apoptosis by suppressing the } \\
\text { anti-apoptosis activity of Bcl-xL }\end{array}$ \\
\hline 282 & PDGFR $\beta$ & 2.39 & Platelet-derived growth factor receptor $\beta$ \\
\hline 291 & PTEN & 2.06 & Phosphatase and tensin homolog; the PTEN gene is a tumor suppressor gene \\
\hline 292 & SH-PTP & 2.33 & SH-protein tyrosine phosphatase 1 \\
\hline 307 & RalA & 2.46 & Small GTPase superfamily; Ras family of proteins \\
\hline 308 & RanBP-1 & 2.31 & Ras-related nuclear protein $\mathrm{BP}-1$ \\
\hline 311 & RARr & 2.18 & Retinoic acid receptors \\
\hline 312 & RXR a,b, r & 2.30 & Retinoid $X$ receptors $a, b, r$ \\
\hline 325 & RIP & 2.39 & Receptor interacting protein \\
\hline 331 & P-Selectin & 3.12 & Cell adhesion molecule \\
\hline 332 & SHC & 2.56 & Src homology 2 domain containing \\
\hline 343 & Blk & 2.27 & Proto-oncogenic non-receptor tyrosine kinase \\
\hline 346 & Lck & 2.72 & Leukocyte-specific protein tyrosine kinase \\
\hline 347 & Lyn & 3.54 & A member of the Src family of protein tyrosine kinases \\
\hline 351 & STAM & 3.59 & Signal transducing adaptor molecule \\
\hline 364 & TANK & 2.68 & TRAF-associated NF- $\kappa \mathrm{B}$ activator \\
\hline 365 & $\mathrm{TCR} \alpha$ & 3.92 & T-cell receptor $\alpha$ \\
\hline 366 & TCR $\beta$ & 4.14 & T-cell receptor $\beta$ \\
\hline 367 & TDAG51 & 3.32 & T-cell death associated gene 51 \\
\hline 370 & Thyroid R $\alpha 1$ & 3.56 & Thyroid hormone nuclear receptor $\alpha 1$ \\
\hline 371 & TIA-1 & 5.52 & A member of an RNA-binding protein family; a mediator of apoptotic cell death \\
\hline 372 & TIAR & 4.06 & TIA receptor \\
\hline 375 & TOSO & 2.57 & \\
\hline 392 & VDR & 2.99 & Vitamin D receptor \\
\hline 394 & VEGFR2 & 2.35 & VEGF receptor 2 \\
\hline 397 & XRCC4 & 2.38 & X-ray repair cross-complementing protein 4 \\
\hline 14 & APC & 0.43 & Adhesion protein \\
\hline 27 & Bcl-2 & 0.42 & B-cell lymphoma 2 \\
\hline 39 & BARD1 & 0.36 & $\begin{array}{l}\text { BRCA1-associated RING domain gene } 1 \text { is a major cellular binding partner } \\
\text { of BRCA1 }\end{array}$ \\
\hline 40 & BRCA1 & 0.42 & Breast cancer 1 \\
\hline 60 & Caspase-5 & 0.49 & Cysteine-aspartic acid protease 5 \\
\hline 100 & CUL-1 & 0.43 & A member of the cullin protein family \\
\hline 118 & DR5 & 0.32 & Death receptor 5 \\
\hline 139 & Ezrin & 0.48 & $\begin{array}{l}\text { Cytoplasmic protein; a major cytoplasmic substrate of various protein-tyrosine } \\
\text { kinases }\end{array}$ \\
\hline 158 & GADD45 & 0.30 & Growth arrest and DNA damage 45 \\
\hline 174 & Ne-dlg & 0.49 & Neuronal and endocrine dlg (Discs large) \\
\hline 175 & hIL & 0.50 & IAP family member \\
\hline 179 & ICSBP & 0.49 & Interferon consensus sequence-binding protein \\
\hline 180 & ID1 & 0.38 & A member of the Id family of basic helix-loop-helix (bHLH) proteins \\
\hline 194 & ITG $\alpha \mathrm{V}$ & 0.12 & Integrin $\alpha$ subunit \\
\hline 195 & ITG $\beta 1$ & 0.12 & Integrin $\beta$ subunit (CD29) \\
\hline 196 & ITG $\beta 3$ & 0.14 & Integrin $\beta$ subunit \\
\hline 197 & IRAK & 0.25 & IL-1 receptor-associated kinase \\
\hline 198 & IRF1 & 0.41 & Interferon regulatory factor-1 \\
\hline 213 & LIFR & 0.41 & Leukemia inhibitory factor receptor \\
\hline
\end{tabular}


Table I. Continued.

\begin{tabular}{|c|c|c|c|}
\hline Position & Symbol & Ratio & Description and function \\
\hline 215 & MAD2 & 0.16 & Mitotic arrest-deficient 2 \\
\hline 216 & Maspin & 0.12 & A serpin and tumor suppressor gene \\
\hline 217 & Max & 0.45 & Transcription factor \\
\hline 218 & MDA-7 & 0.40 & Melanoma differentiation-associated protein-7 \\
\hline 220 & MRP-2 & 0.47 & Multiple drug resistance protein \\
\hline 235 & NF1GRP & 0.27 & Neurofibromin protein \\
\hline 237 & NFATC & 0.46 & Nuclear factor of activated T-cells, cytoplasmic, calcineurin-dependent \\
\hline 238 & NF- $\kappa$ B-p50 & 0.40 & Nuclear factor- $\kappa \mathrm{B} 50$ \\
\hline 256 & Notch & 0.46 & A human gene encoding a single-pass transmembrane receptor \\
\hline 278 & Pax-5 & 0.48 & Nuclear transcription factor \\
\hline
\end{tabular}

Table II. Inhibition rate and Q values of cisplatin in combination with rVBMDMP on A549/DDP cell growth.

\begin{tabular}{|c|c|c|c|c|}
\hline Group & Growth inhibition rate (\%) & $\mathrm{Q}$ value & Cisplatin $\mathrm{IC}_{50}$ & Reversal index (RI) \\
\hline $\operatorname{DDP}(10 \mu \mathrm{g} / \mathrm{ml})$ & $12.8 \pm 5.6$ & & 31.19 & \\
\hline $\operatorname{DDP}(20 \mu \mathrm{g} / \mathrm{ml})$ & $32.9 \pm 7.1$ & & & \\
\hline $\mathrm{DDP}(40 \mu \mathrm{g} / \mathrm{ml})$ & $52.0 \pm 10.2$ & & & \\
\hline $\mathrm{DDP}(10 \mu \mathrm{g} / \mathrm{ml})+\mathrm{rVBMDMP}(10.0 \mu \mathrm{M})$ & $45.2 \pm 8.5$ & 0.88 & 11.82 & 2.639 \\
\hline DDP $(20 \mu \mathrm{g} / \mathrm{ml})+\mathrm{rVBMDMP}(10.0 \mu \mathrm{M})$ & $66.9 \pm 8.9$ & 1.15 & & \\
\hline DDP $(40 \mu \mathrm{g} / \mathrm{ml})+\mathrm{rVBMDMP}(10.0 \mu \mathrm{M})$ & $89.1 \pm 12.3$ & 1.22 & & \\
\hline
\end{tabular}

A $Q$ value of $0.85-1.15$ represents the summation effects of the two drugs; a $Q$ value $>1.15$ indicates a synergistic effect of the two drugs; a $\mathrm{Q}$ value $<0.85$ indicates an antagonistic effect of the two drugs. rVBMDMP, recombinant VBMDMP.

$40 \mu \mathrm{g} / \mathrm{ml}$ cisplatin alone, the growth inhibition rate was $52 \pm 10.2 \%$ and the inhibitory rate increased to $89.1 \pm 12.3 \%$ when combined with $10 \mu \mathrm{M} \mathrm{rVBMDMP}$. The Q value was 1.22. According to the formula $\mathrm{IC}_{50}=\lg ^{-1}[\mathrm{Xm}-\mathrm{i}(\mathrm{P}-0.5)]$, the $\mathrm{IC}_{50}$ was $11.82 \mu \mathrm{g} / \mathrm{ml}$ when combined with $10 \mu \mathrm{M} \mathrm{rVBMDMP}$ in A549/DDP cells. Thus, the multidrug resistance reversal index (RI) was 2.639. Together, these results demonstrated that the combined application of rVBMDMP with cisplatin produced an additive inhibition to significantly reduce A549/DDP cell survival.

We next evaluated A549/DDP cell apoptosis after cisplatin and rVBMDMP treatment using Hoechst 33258 staining (Fig. 2C). Apoptotic cells were observed after treatment with $10 \mu \mathrm{M} \mathrm{rVBMDMP}$ or $10 \mu \mathrm{g} / \mathrm{ml}$ cisplatin alone for $48 \mathrm{~h}$. However, the combination of these 2 drugs markedly enhanced A549/DDP cell apoptosis compared with the control group, which underwent little apoptosis. The nuclei as observed by normal fluorescence microscopy were large and evenly stained; pyknotic nuclei appeared smaller and the nuclear chromatin was densely stained towards the edge or showed chunky dense staining in apoptotic cells.

As shown in Fig. 2D, caspase-3 was mildly activated (cleaved) in the A549/DDP cells following treatment with rVBMDMP alone and was nearly completely cleaved when combined with cisplatin. PARP cleavage showed a similar trend. This suggests that combined treatment causes caspase-3 activation, thereby inducing apoptosis and PARP cleavage. This may be coupled with MRP-2 downregulation, which then blocks cisplatin cellular efflux. This may be one of the mechanisms involved in the reversal of A549/DDP cell chemotherapeutic resistance by rVBMDMP.

rVBMDMP and cisplatin treatment in combination significantly inhibit survival. We next investigated the molecular mechanism by which the combination treatment of rVBMDMP and cisplatin mediates anti-survival effects in A549/DDP cells.

After treatment with $10 \mu \mathrm{M}$ rVBMDMP alone, A549/DDP cells showed downregulation of MRP-2, integrin $\alpha \mathrm{V}$ and $\mathrm{NF}-\kappa \mathrm{B}$ p50 protein expression, while cisplatin alone had no effect on MRP-2, Bcl-2, integrin $\alpha \mathrm{V}$ or $\mathrm{NF}-\kappa \mathrm{B}$ p50 protein expression (Fig. 3A). However, upon the combination treatment of cisplatin and rVBMDMP, levels of the above proteins were significantly reduced compared with the controls. rVBMDMP downregulation of MRP-2, integrin $\alpha \mathrm{V}$ and NF- $\mathrm{B}$ p50 protein expression may be related to the reversal of A549/DDP cell drug resistance.

Total PI3K and Akt protein levels were not altered in all 4 A549/DDP cell treatment groups, while PI3K/Akt protein phosphorylation was markedly decreased following $10 \mu \mathrm{M}$ rVBMDMP treatment, indicating that rVBMDMP 
A

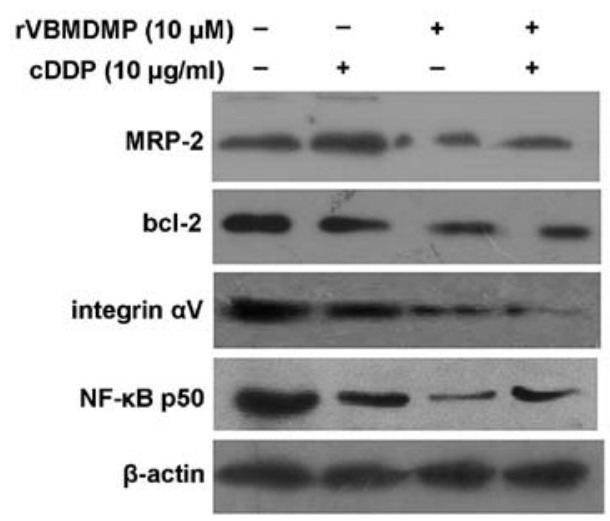

B

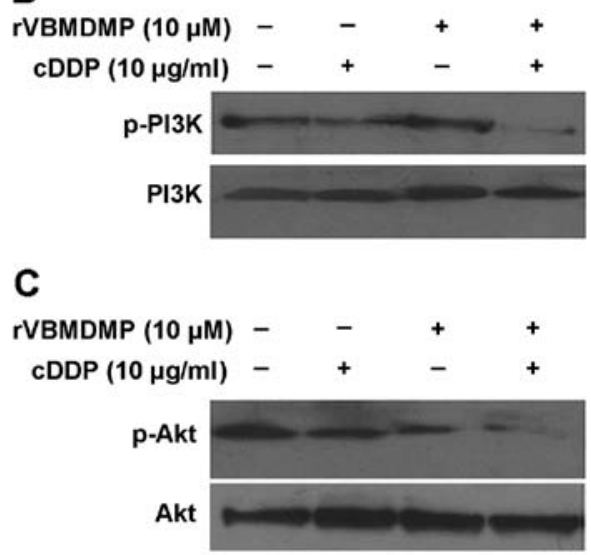

Figure 3. Combination of cisplatin and rVBMDMP significantly inhibits A549/DDP cell survival signal. A549/DDP cells were cultured in RPMI-1640 with cisplatin, rVBMDMP, or the combination of cisplatin and rVBMDMP as indicated for $48 \mathrm{~h}$. (A) Cells were collected and subjected to western blot analyses with specific antibodies against multidrug resistance protein 2 (MRP-2), Bcl-2, integrin $\alpha \mathrm{V}, \mathrm{NF}-\kappa \mathrm{B}$ (P50) and $\beta$-actin. (B and C) Western blot analysis of cell treated as in A for phosphatidylinositol 3 kinase (PI3K) and Akt protein expression and phosphorylation in cultured A549/DDP cells. DDP, cisplatin; rVBMDMP, recombinant VBMDMP.

A

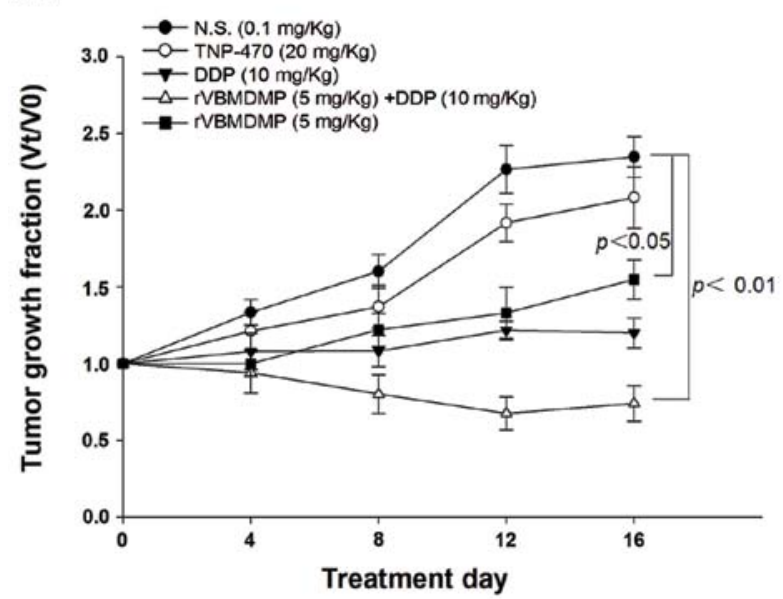

C

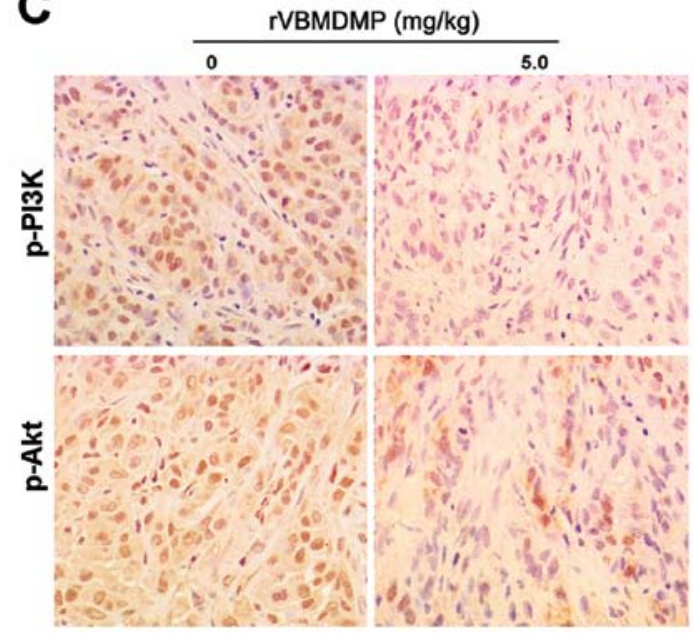

B

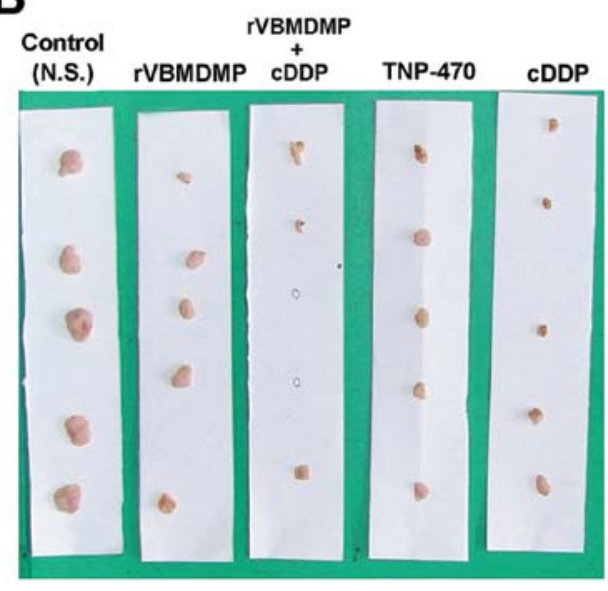

D

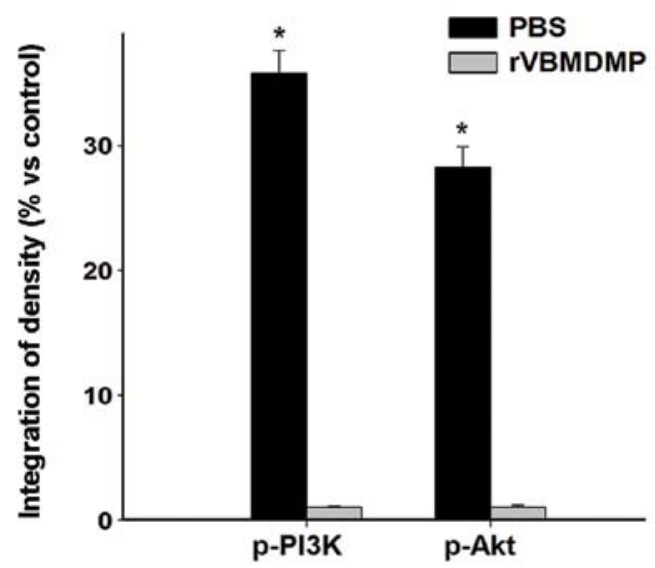

Figure 4. Effects of rVBMDMP on primary human lung carcinoma xenograft models in nude mice. (A) Growth inhibition of A549/DDP human lung carcinoma xenografts treated as indicated. Cells $\left(2 \times 10^{6}\right)$ were injected subcutaneously into 4 - to 5-week-old female athymic nude mice. rVBMDMP $(5 \mathrm{mg} / \mathrm{kg})$ alone or in combination with cisplatin $(10 \mathrm{mg} / \mathrm{kg}$ ) was injected intravenously twice daily for 16 days. The control group received the saline vehicle. TNP-470, an angiogenesis inhibitor, and cisplatin were used as positive controls. The tumors were allowed to grow to $\sim 100 \mathrm{~mm}^{3}$. Each point represents the mean $\pm \mathrm{SD}$ of 5 mice per group. (B) Image of solid tumors obtained after 16 days of treatment. (C) Immunohistochemistry of phosphorylated phosphatidylinositol 3 kinase (PI3K) and phosphorylated Akt in endpoint tumors in the rVBMDMP $(5 \mathrm{mg} / \mathrm{kg}$ )-treated and control groups. (D) Integrated density measurements for p-pI3K and p-Akt shown as mean \pm SD. ${ }^{*} \mathrm{P}<0.01$ vs. control ( $\mathrm{n}=5$ fields/group). DPP, cisplatin; rVBMDMP, recombinant VBMDMP. 
inhibited PI3K and Akt phosphorylation in the A549/DDP cells (Fig. 3B and C). Phosphorylated PI3K/Akt levels were not altered in the cisplatin-treated group. These data suggest that the PI3K/Akt signal transduction pathway may be associated with the rVBMDMP-mediated reversal of multidrug resistance.

rVBMDMP-mediated human lung carcinomaxenograftgrowth inhibition in $B A L B / c$ nude mice. To investigate the inhibition of rVBMDMP on A549/DDP cell growth in vivo, we examined the effects of rVBMDMP on established primary human lung carcinoma xenograft models in nude mice. Our results showed that rVBMDMP significantly inhibited human lung carcinoma xenograft growth (Fig. 4). rVBMDMP treatment decreased the tumor growth rate as evaluated by measurement of the tumor volume at regular intervals (Fig. 4A). Administration of $5 \mathrm{mg} /$ $\mathrm{kg}$ rVBMDMP combined with $10 \mathrm{mg} / \mathrm{kg}$ cisplatin resulted in 37 and 74\% reduction in tumor volume, respectively (Fig. 4B). After 16 days of treatment, the final wet tumor weight in the $5 \mathrm{mg} / \mathrm{kg}$ rVBMDMP-treated group was reduced by $77 \%$ $(\mathrm{P}<0.05)$, whereas the tumor weight was reduced by $4 \%$ after TNP $470(20 \mathrm{mg} / \mathrm{kg})$ treatment and $42 \%$ after cisplatin $(10 \mathrm{mg} /$ $\mathrm{kg}$ ) treatment.

\section{Discussion}

Our previous research determined that rVBMDMP and the tumstatin 197-215 amino acid peptide can significantly inhibit tumor cell (A549 and SW480 cells) proliferation and growth in a dose-dependent manner, $(3,7)$ while there were no significant effects on normal human embryo lung (KMB-17) and Chinese hamster ovary (CHO-K1) cell proliferation and growth. These results indicate that rVBMDMP not only preserves the antitumor activity of the tumstatin 197-215 amino acid peptide but also has relative selectivity to cancer cells compared with normal cell lines. rVBMDMP significantly inhibited human lung and colon cancer xenograft growth in nude mice in a dose-dependent manner (3). Therefore, the tumstatin 197-215 amino acid peptide as part of rVBMDMP may be responsible for its inhibition of tumor cell proliferation and growth. Shahan et al confirmed that the tumstatin N-terminal 197-215 peptide exhibits biological function by binding integrin $\alpha \mathrm{V} \beta 3$ on the tumor cell surface (11). However, the underlying detailed mechanism is not clear. Our previous study confirmed that rVBMDMP also binds integrin $\alpha \mathrm{V} \beta 3$ (4).

Integrin $\alpha \mathrm{V} \beta 3$ expression is highly cell specific, with nearly no expression on the surface of resting endothelial cells and some normal cells, such as hepatic stellate cells (12). However, $\alpha \mathrm{V} \beta 3$ expression is significantly higher in lung adenocarcinoma A549 cells (13), prostate cancer (14) and breast cancer (15). Integrin has a bidirectional signal transmission function: its outward intracellular signal transduction regulates cell adhesion and migration, while integrin ligand binding triggers signals to regulate cell growth, differentiation and apoptosis $(16,17)$. In the present study, the antibody array results revealed that rVBMDMP treatment can downregulate integrin $\alpha \mathrm{V} \beta 3$ subunit phosphorylation in A549 cells, suggesting effects on its downstream pleiotropic and complex signal transduction.

Integrin signal transduction is closely related to FAK activation $(18,19)$. FAK is a cytoplasmic non-receptor tyrosine kinase and its activation is accompanied by the accumulation of focal adhesion. The FAK signal transduction pathway can be activated substantially by integrins. Activated FAK binds multiple intracellular proteins that contain $\mathrm{SH} 2$ domains, thus activating several signaling pathways. Among these is the PI3K/ Akt pathway, on which we previously focused our studies (20). PI3K regulates signaling pathways that are involved in multiple cellular functions including survival, proliferation, apoptosis, cell differentiation and cytoskeleton structure. PI3K is a phosphoinositide-dependent kinase family member that specifically catalyzes PI-4,5-P2 and Ptdlns-4-P to generate Ptdlns-3, 4, 5-P3 and Ptdlns-3, 4-P2, respectively. The last 2 multi-phosphatidylinositol derivatives have biological roles as messenger molecules by binding and activating Akt, thus causing tumor cell proliferation and inhibiting apoptosis (21), which is an important cause of tumor drug resistance (22). Thus, the PI3K pathway may play a role in multidrug resistance (23). FAK can recruit and directly activate PI3K, which activates its downstream target Akt.

Akt is a main target of PI $3 \mathrm{~K}$ and is closely related to a variety of cell biological behaviors such as metabolism regulation, cell survival and particularly apoptosis $(24,25)$. Activation of key survival signaling molecules such as PI3K/Akt, especially increasing Akt phosphorylation levels, is not only closely related to cancer cell development and apoptosis inhibition but is also a main step leading to multidrug resistance $(26,27)$. Activated Akt can promote cell growth and proliferation by phosphorylating downstream molecules such as mammalian target of rapamycin (mTOR), p27 $7^{\mathrm{WAF} / / \mathrm{Cipl}}$, GSK3 and tuberous sclerosis complex 2 (TSC2) $(28,29)$. It also inhibits apoptosis via NF- $\kappa$ B and 14-3-3 phosphorylation-mediated downregulation of FasL-induced apoptosis protein $(30,31)$ as well as phosphorylation of several apoptosis-related molecules including Bcl-2 family members such as Bcl-2, Bcl-xL and Bcl-xs $(32,33)$, inhibitor of apoptosis protein family members (IAPs) (34) and caspase-8, -9 and -3 (35), which inhibit apoptosis, thus inducing cancer cell chemotherapeutic drug resistance (36). Our results demonstrated that rVBMDMP treatment of lung cancer cells also affected integrin-FAK pathway signal transduction by downregulating FAK, PI3K, Akt and NF- $\mathrm{BB}$ survival signaling molecule phosphorylation and further affecting A549/DDP lung cancer survival cell signaling, weakening its cell survival ability and even directly inducing apoptosis.

Here, we determined that rVBMDMP treatment when combined with cisplatin can reverse A549/DDP cell multidrug resistance. This result was displayed by i) a significantly decreased cisplatin $\mathrm{IC}_{50}$ in A549/DDP cells and (2) significantly decreased MRP expression in A549/DDP cells. The results obtained from the animal experiments also demonstrated that rVBMDMP treatment combined with cisplatin can effectively inhibit A549/DDP cell growth in nude mice. These data suggest that rVBMDMP is not only an effective antitumor drug, but it can also reverse the resistance of A549/DDP cells to cisplatin.

Chemotherapy resistance is a major cause of non-small cell lung carcinoma (NSCLC) chemotherapy failure and disease progression, and chemotherapy tolerance-induced tumor cell apoptosis is an important mechanism of tumor resistance. Cisplatin is a commonly used drug with a high curative effect 
on lung cancer. Cisplatin resistance is often indicative of multidrug resistance, the phenomenon in which cells exhibit insensitivity to many types of chemotherapy drugs. Therefore, clinical follow-up treatment for patients with cisplatin resistance is often difficult.

Multidrug resistance consists of a complex mechanism, in which MRP-2 plays a major role. MRP-2, also called multispecific organic anion transporter (cMOAT), functions as a transport protein for organic anions and a variety of drugs (37). MRP-2 is considered as the mediator of cisplatin resistance, as neither P-gp nor MRP1, related multidrug resistance proteins, recognize cisplatin as substrate. Ishikawa et al first demonstrated that the MRP-2/GS-X pump could transport glutathione-cisplatin conjugates from the cells, which mediates tumor cell resistance to cisplatin (38). The authors determined that the glutathione $\mathrm{S}$ efflux pump activity in tumor cells with high MRP-2 expression was enhanced, suggesting that MRP-2 can identify and transport glutathione-drug conjugates and promote tumor drug or modified product efflux to produce multidrug resistance (39). The present study also observed downregulation of PI3K/ Akt phosphorylation in human lung cancer A549/DDP cells following rVBMDMP treatment, weakening survival signaling. Expression of anti-apoptotic proteins $\mathrm{Bcl}-2$ and MRP-2 were also reduced, thus weakening the anti-apoptotic ability and the drug pumping effect of cisplatin-resistant cells. It has been suggested that rVBMDMP can weaken A549/DDP cell tolerance to cisplatin, enhance cisplatin sensitivity, facilitate endogenous cisplatin-induced apoptosis signals and even reverse the drug resistance traits of A549/DDP cells. Above are some of the molecular mechanisms by which rVBMDMP increases chemotherapy sensitivity and reverses the effects of multidrug resistance. These results suggest that the antitumor activity of rVBMDMP on A549 lung cancer cells was not related to A549/DDP cell drug resistance, indicating there is no cross resistance to cisplatin and rVBMDMP. Conversely, these results also suggest that cisplatin and rVBMDMP affect different pathways. Therefore, rVBMDMP treatment can still have favorable effects for patients suffering from cisplatinresistant lung adenocarcinoma.

In conclusion, the results of this study provide a theoretical and experimental basis for further evaluation of the molecular mechanisms of rVBMDMP in regulating tumor cell signaling networks and reversing drug resistance in lung cancer.

\section{Acknowledgements}

This study was supported by the Natural Science Foundation of Guangdong Province (grant no. S2012010008995) and the Doctoral Fund of the Education Ministry of China (grant no. 20124423110003.

\section{References}

1. Peng SP, Fang WY, Dai WJ, Zou XQ, Liu HY and Cao JG: Cloning expression and space conformation analysis of vascular basement membrane-derived multifunctional peptide. Chinese J Cancer Biother 10: 185-189, 2003.

2. Peng SP, Fang WY, Jiang RC, Zhou JG and Cao JG: Prokaryotic expression of vascular basement membrane-derived multifunctional peptide and its anti-tumor activity assay. Zhongguo Yaolixue Tongbao 19: 678-682, 2003.
3. Cao JG, Peng SP, Sun L, Li H, Wang L and Deng HW: Vascular basement membrane-derived multifunctional peptide, a novel inhibitor of angiogenesis and tumor growth. Acta Biochim Biophys Sin (Shanghai) 38: 514-521, 2006.

4. Wang C, Cao J, Qu J, Li Y, Peng B, Gu Y and He Z: Recombinant vascular basement membrane derived multifunctional peptide blocks endothelial cell angiogenesis and neovascularization. J Cell Biochem 111: 453-460, 2010.

5. Desgrosellier JS and Cheresh DA: Integrins in cancer: biological implications and therapeutic opportunities. Nat Rev Cancer 10: 9-22, 2010.

6. Long QZ, Zhou M, Liu XG, Du YF, Fan JH, Li X and He DL: Interaction of $\mathrm{CCN} 1$ with $\alpha v \beta 3$ integrin induces P-glycoprotein and confers vinblastine resistance in renal cell carcinoma cells. Anticancer Drugs 24: 810-817, 2013.

7. Wang CK, Cao JG, Peng B, Gu YX, Zheng GP and He ZM: Inhibition of growth and motility of human A549 lung carcinoma cells by a recombined vascular basement membrane derived peptide. Cancer Lett 292: 261-268, 2010.

8. Scheer N, Balimane P, Hayward MD, Buechel S, Kauselmann G and Wolf CR: Generation and characterization of a novel multidrug resistance protein 2 humanized mouse line. Drug Metab Dispos 40: 2212-2218, 2012.

9. Tiwari AK, Sodani K, Dai CL, et al: Nilotinib potentiates anticancer drug sensitivity in murine ABCB1-, ABCG2- and ABCC10-multidrug resistance xenograft models. Cancer Lett 328: 307-317, 2013.

10. Laitinen EM, Vaaralahti K, Tommiska J,Eklund E, Tervaniemi M, Valanne L and Raivio T: Incidence, phenotypic features and molecular genetics of Kallmann syndrome in Finland. Orphanet J Rare Dis 6: 41, 2011.

11. Shahan TA, Ziaie Z, Pasco S, Fawzi A, Bellon G, Monboisse JC and Kefalides NA: Identification of CD47/integrin-associated protein and alpha(v)beta3 as two receptors for the alpha3(IV) chain of type IV collagen on tumor cells. Cancer Res 59: 4584-4590, 1999.

12. Huang XW, Wang JY, Li F, Song ZJ, Xie C and Lu WY: Biochemical characterization of the binding of cyclic RGDyK to hepatic stellate cells. Biochem Pharmacol 80: 136-143, 2010.

13. Huang CY, Fong YC, Lee CY, Chen MY, Tsai HC, Hsu HC and Tang CH: CCL5 increases lung cancer migration via PI3K, Akt and NF-kappaB pathways. Biochem Pharmacol 77: 794-803, 2009.

14. Ummanni R, Teller S, Junker H, et al: Altered expression of tumor protein D52 regulates apoptosis and migration of prostate cancer cells. FEBS J 275: 5703-5713, 2008.

15. Jiang P, Enomoto A and Takahashi M: Cell biology of the movement of breast cancer cells: intracellular signalling and the actin cytoskeleton. Cancer Lett 284: 122-130, 2009.

16. Winograd-Katz SE, Fassler R, Geiger B and Legate KR: The integrin adhesome: from genes and proteins to human disease. Nat Rev Mol Cell Biol 15: 273-288, 2014.

17. Bouvard D, Pouwels J, De Franceschi N and Ivaska J: Integrin inactivators: balancing cellular functions in vitro and in vivo. Nat Rev Mol Cell Biol 14: 430-442, 2013.

18. Hu P and Luo BH: Integrin bi-directional signaling across the plasma membrane. J Cell Physiol 228: 306-312, 2013.

19. Yin B: Focal adhesion kinase as a target in the treatment of hematological malignancies. Leuk Res 35: 1416-1418, 2011.

20. Riaz A, Ilan N, Vlodavsky I, Li JP and Johansson S: Characterization of heparanase-induced phosphatidylinositol 3-kinase-AKT activation and its integrin dependence. J Biol Chem 288: 12366-12375, 2013.

21. Guenther MK, Graab U and Fulda S: Synthetic lethal interaction between PI3K/Akt/mTOR and Ras/MEK/ERK pathway inhibition in rhabdomyosarcoma. Cancer Lett 337: 200-209, 2013.

22. Choi BH, Kim CG, Lim Y, Shin SY and Lee YH: Curcumin downregulates the multidrug-resistance mdrlb gene by inhibiting the PI3K/Akt/NF kappa B pathway. Cancer Lett 259: 111-118, 2008.

23. Goler-Baron V, Sladkevich I and Assaraf YG: Inhibition of the PI3K-Akt signaling pathway disrupts ABCG2-rich extracellular vesicles and overcomes multidrug resistance in breast cancer cells. Biochem Pharmacol 83: 1340-1348, 2012.

24. Konopleva MY, Walter RB, Faderl SH, et al: Preclinical and early clinical evaluation of the oral AKT inhibitor, MK-2206, for the treatment of acute myelogenous leukemia. Clin Cancer Res 20: 2226-2235, 2014.

25. Neri LM, Cani A, Martelli AM, et al: Targeting the PI3K/ Akt/mTOR signaling pathway in B-precursor acute lymphoblastic leukemia and its therapeutic potential. Leukemia 4: 739-748, 2014. 
26. Chen KC, Yang TY, Wu CC, et al: Pemetrexed induces S-phase arrest and apoptosis via a deregulated activation of Akt signaling pathway. PLoS One 9: e97888, 2014.

27. Wang F, Li T, Zhang B, et al: MicroRNA-19a/b regulates multidrug resistance in human gastric cancer cells by targeting PTEN. Biochem Biophys Res Commun 434: 688-694, 2013.

28. Ning J and Clemmons DR: AMP-activated protein kinase inhibits IGF-I signaling and protein synthesis in vascular smooth muscle cells via stimulation of insulin receptor substrate $1 \mathrm{~S} 794$ and tuberous sclerosis 2 S1345 phosphorylation. Mol Endocrinol 24: 1218-1229, 2010.

29. Liu L, Dai Y, Chen J, et al: Maelstrom promotes hepatocellular carcinoma metastasis by inducing epithelial-mesenchymal transition by way of Akt/GSK-3 $\beta /$ Snail signaling. Hepatology 59: 531-543, 2014

30. Bak Y, Kim H, Kang JW, et al: A synthetic naringenin derivative, 5-hydroxy-7,4'-diacetyloxyflavanone-N-phenyl hydrazone (N101-43), induces apoptosis through up-regulation of Fas/FasL expression and inhibition of PI3K/Akt signaling pathways in non-small-cell lung cancer cells. J Agric Food Chem 59: 10286-10297, 2011.

31. Krzyzowska M, Shestakov A, Eriksson K and Chiodi F: Role of Fas/FasL in regulation of inflammation in vaginal tissue during HSV-2 infection. Cell Death Dis 2: e132, 2011.

32. Shenoy AR, Kirschnek S and Hacker G: IL-15 regulates Bcl-2 family members Bim and Mcl-1 through JAK/STAT and PI3K/AKT pathways in T cells. Eur J Immunol: 2500-2507, 2014.
33. Bogdal MN, Hat B, Kochanczyk M and Lipniacki T: Levels of pro-apoptotic regulator Bad and anti-apoptotic regulator Bcl-xL determine the type of the apoptotic logic gate. BMC Syst Biol 7: 67, 2013.

34. Gravina GL, Marampon F, Giusti I, et al: Differential effects of PXD101 (belinostat) on androgen-dependent and androgen-independent prostate cancer models. Int J Oncol 40: 711-720, 2012.

35. Wang TE, Wang YK, Jin J, Xu BL and Chen XG: A novel derivative of quinazoline, WYK431 induces G2/M phase arrest and apoptosis in human gastric cancer BGC823 cells through the PI3K/Akt pathway. Int J Oncol 45: 771-781, 2014.

36. Liu Z, Sun C, Zhang Y, Ji Z and Yang G: Phosphatidylinositol 3-kinase-C2 $\beta$ inhibits cisplatin-mediated apoptosis via the Akt pathway in oesophageal squamous cell carcinoma. J Int Med Res 39: 1319-1332, 2011.

37. Le Vee M, Jouan E, Stieger B, Lecureur V and Fardel O: Regulation of drug transporter expression by oncostatin $M$ in human hepatocytes. Biochem Pharmacol 82: 304-311, 2011.

38. Ishikawa T, Wright $\mathrm{CD}$ and Ishizuka H: GS-X pump is functionally overexpressed in cis-diamminedichloroplatinum (II)-resistant human leukemia HL-60 cells and down-regulated by cell differentiation. J Biol Chem 269: 29085-29093, 1994.

39. Kibria G, Hatakeyama $\mathrm{H}$ and Harashima $\mathrm{H}$ : Cancer multidrug resistance: mechanisms involved and strategies for circumvention using a drug delivery system. Arch Pharm Res 37: 4-15, 2014. 